\title{
Thoughts on Human Resource Management of Private Enterprises in China
}

\author{
HU Zheng ${ }^{1, a}$
}

\author{
${ }^{1}$ Hankou University, Wuhan, Hubei, China \\ a471834856@qq.com
}

\begin{abstract}
Human resources exert a great strategic significance in the operation and development of private enterprises especially in the role of upgrading their core competitiveness. However, the present situation of human resource management has become a prominent factor limiting the development of private enterprises in China. Thus, the urgent appeal facing the majority of private enterprises is how to scientifically and effectively discover the value of human resource management and development. To dive into this topic, this paper summarizes the main problems existing in human resource management of private enterprises in China, and proposes targeted countermeasures and suggestions, hoping to offer a scientific foundation for promoting their sustainable development.
\end{abstract}

Keywords: private enterprises, human resource management, problems, countermeasures

\section{中国民营企业人力资源管理问题思考}

胡征 ${ }^{1, a}$

${ }^{1}$ 汉口学院, 武汉, 湖北, 中国
${ }^{a} 471834856$ qq.com

摘要：人力资源对于民营企业提升核心竞争力具有重大的战略意义，在企业经营发展中占据着重要地位。但 是目前制约中国民营企业发展的一个主要问题就是人力资源管理,如何科学有效地发挥人力资源管理与开发的 价值, 是广大民营企业亟待解决的突出难题。对此通过分析我国民营企业在人力资源管理中所存在的主要问题, 提出有针对性地对策和建议, 以期促进民营企业的可持续发展提供科学的依据。

关键词：民营企业；人力资源管理；问题；对策

1. 引言

现代企业之间的竞争就是人才的竞争，提高人力 资源管理与开发的水平, 为企业创造价值, 对提升中 国民营企业的核心竞争力有着极其重要的现实意义。

\section{2. 中国民营企业人力资源管理存在的主要问} 题

\section{1. 缺乏现代人力资源管理理念}

首先，在管理行为上，民营企业主对每项工作都 非常喜欢事必躬亲、事无巨细，奉行简单管理、人治 管理以及 “一竿子插到底” 的直接管理风格, 导致组 织层级完全被打乱, 每个员工都以民营企业主为中 心，凡事都直接跟民营企业主直接汇报，以至于企业
缺乏完善的流程规范，人力管理制度几乎为零，全凭 民营企业主的一时心血来潮，工作指令频繁变更，随 意性大。有的民营企业虽然制定了详细的管理制度, 但在具体执行时，还是依照民营企业主的主观意识来 行事, 并没有严格按照规矩办事, 把制度落到实处, 造成有制度无行动, 有行动无执行。其次, 很多民营 企业主打心底里就认为人力资源的工作只不过是平 时签到考勤、打打电话、谈谈薪酬、月底算算工资, 无法为企业创造效益，导致很多民营企业并没有真正 意义上的人力资源部门，虽然有些具有一定规模的民 营企业设置了专门的人力资源管理部，但是其管理职 能偏重于协调和行政范畴, 并没有发挥出人力资源管 理与开发的价值 ${ }^{1}$ 。再次，有些民营企业主虽然认识 到了人力资源管理对于企业的重要性, 但缺乏现代人 力资源管理的专业知识, 对员工的管理还是习惯于通 
过 “驾驭” 来驱动企业的发展, 忽视了开发员工的才 能和激发员工的积极性做好工作来提升企业的绩效。 究其原因, 在于民营企业主未树立起人力资源开发利 用的理念，尚未意识到企业的 “人力” 是一种 “有思 想的”、“有意识的” 可再生性的资源, 需要持续地 开发、有效地利用其价值, 使企业永葆活力。

\section{2 民营企业人员流动频繁}

民营企业在发展初期，基于成本和信任的因素， 员工一般由家族成员或亲朋好友组成，随着企业规模 的扩大和业务多元化的发展, 现有员工的专业知识难 以支撑新业务的发展, 临时培训和培养又来不及, 只 能紧急从社会上招聘, 而一项新业务的开展需要一个 摸索的过程, 加上人力资源部处于弱化地位, 与用人 部门沟通不畅, 造成在招聘环节中, 定责、定岗、定 编、定员模糊不清, 导致花费大量时间和精力外聘来 的人员要么小材大用, 不能胜任本职工作, 无法完成 目标业绩而淘汰; 要么大材小用, 无法发挥自己的才 能推动企业业务的发展, 最终壮志未酬辞职离开 ${ }^{2}$ 。

其次, 在工作中, 会出现家族成员与外聘员工的多重 冲突, 或是意见不统一, 或是工作授权产生矛盾, 再 或是没有专业化知识的家族成员身居高位, 真正懂专 业技术的外聘人才为其下属, 出现外行领导内行的情 况, 使外聘员工觉得自己是一个 “外人”, 难以得到 信任甚至是起码的尊重, 导致 “平民百姓” 员工和 “皇 亲国戚” 员工间的心理隔阂, 致使骑驴找马的 “打工 心态” 充斥着外聘员工的心理。再次, 一方面, 一些 民营企业因产品技术、市场销量、发展方向等原因, 导致企业前景不明朗, 每月的工资都无法按时正常发 放, 使员工感到前途未卜。另一方面, 还有一些民营 企业内部疏于管理, 造成分工不清、权责不明, 导致 员工无论再怎么努力工作, 都无法达到民营企业主的 要求, 再或是管理制度过于严苛, 罚多于奖, 员工长 期在处罚和开除的心理压力下工作, 缺乏职业稳定感 和工作安全感, 一发现好的工作机会就会跳槽。还有 的管理人员, 要求 24 小时手机备勤, 随叫随到, 长 此以往, 身体扛不住只能选择离职。最后, 90 后、 00 后的新时代人才对职业的期望值不断提高, 与自 身专业的匹配度、企业的工作环境、个人的自由时间、 自己是否喜欢这个工作成为了个人职业的主要考量, 薪酬待遇反倒是其次。

\section{3 缺乏科学的人才选拔和培训机制}

随着企业的不断发展, 企业在人才选拨、人才培 养方面的弊端不断显现。首先, 人力资源部人员自身 专业素养不高, 虽天天忙于招聘, 但缺乏科学的岗位 需求分析及胜任能力分析, 企业需要什么样的人? 应 该承担何种岗位职责? 一个岗位需要具备什么样素 质的人才? 完全不知。招聘工作没有规范的流程和严 格的标准要求, 仅仅是人力资源部人员通知应聘者直 接与民营企业主面试, 确定是否录用, 而没有联合业 务部门运用笔试法、无领导小组讨论、情景模拟、心
理测评来综合考察应聘者的工作技能、专业知识、性 格特征和人际交往能力等。甚至对应聘人员的学历、 背景和经历都没有核验，只为完成民营企业主交代的 工作任务, 造成滥笔充数。其次, 缺乏与企业发展相 适应的后备人才储备, 常常是企业主临时起意招聘。 另有部分民营企业主将人才当作普通商品, 迷信所谓 的高端人才, 认为只要肯花钱就能招聘到为自己企业 带来利润的员工, 盲目高薪聘请外部人员, 当发现高 薪人才没能发挥作用时, 就随时开除。再次, 某些民 营企业选拨人才仅凭企业主个人的喜怒或员工在个 别工作上的表现, 今天是实习生, 明天提拔为部门经 理, 后天升职成为副总, 大后天就离职了。“得宠” 提拔, “失宠” 开除, 选拨措施灵活但缺乏科学性, 以至于人才晋升机制不合理。最后，大多数民营企业 主只注重短期效益, 更倾向于使用已具备一定经验和 技术水平的成熟人才为企业获取利润，只想 “招来即 用”, 并不愿意为提高企业员工的专业技能进行投资, 导致现有员工特别是年轻员工缺乏学习的机会及发 展的空间。“人” 是一种可开发的资源, 虽然不少民 营企业也都在开展培训和继续教育, 但培训是否为达 成企业的业绩目标、是否是在深入分析了企业业务需 求的基础上设计开展的, 是否为企业创造了价值, 均 值得分析和思考。实际上大多数民营企业无论是培训 的科学性, 还是实效性都没有达到人力资源开发的要 求。

\section{4 激励机制和薪酬制度不合理}

大多数民营企业缺乏科学的激励机制, 具体表现 为二种形式。表现一, 激励的随意性。很多民营企业 没有一个明确的奖惩制度, 奖罚完全凭企业领导个人 的喜好, 存在着承诺不兄现, 奖少罚多的现象, 不光 是经济上扣罚, 还在个人人格上进行侮辱, 致使员工 对企业缺乏归属感, 抱着 “打短工” 的心态, 由此产 生向合作方或竞争对手内外勾结出卖企业商业秘密, 破坏企业资产, 挖走客户等恶性竞争行为。表现二、 激励的单一性。随着人们物质生活的提高, 员工把追 求的目标从基本的温饱需求上升到高层次的精神需 求, 多数民营企业主还认为现在的员工只为保住职位 以求温饱, 简单地通过物质手段对员工进行激励, 忽 略了员工的职位晋升机会、工作成就感、工作满意度 及个人的职业生涯发展规划, 导致员工自我发展空间 受限, 使得人才不得不跳槽到其他企业。加上大多数 民营企业缺乏合理的薪酬制度体系，由于民营企业特 别是中小微民营企业受企业实力的限制, 加上企业领 导为降低运营成本，导致大多数中小微民营企业员工 的薪酬处于 25 分位值, 即市场上 $75 \%$ 的企业比该薪 酬水平高, $25 \%$ 的企业比该薪酬水平低。而对于企业 当前所急需的个别人才采用协议工资制，民营企业主 与应聘者进行薪酬谈判, 采用高薪策略应急使用, 并 没有根据市场薪酬水平、工作内容及对企业的贡献来 制定薪酬, 主观性较大, 导致企业新员工与老员工因 工资标准产生矛盾，产生同工不同酬、同酬不同工的 现象, 造成老员工的心态失衡, 挫伤了老员工的工作 
积极性，使老员工在心理上由一个长期追随者转变成 一个短期打工者，不再打算与企业共进退，致使许多 民营企业留不住、进不来优秀人才 ${ }^{2}$ 。

\section{3. 中国民营企业改善人力资源管理的对策和 建议}

\section{1 树立现代化的人力资源管理理念}

首先，民营企业主在繁忙的工作之余，应抽出宝 贵的时间学习现代人力资源管理的相关知识, 开发员 工的生产力, 建立与本企业自身特点相适应的管理方 法, 摒弃传统的 “人治” 管理模式，提升企业的绩效。 其次, 民营企业要树立起人力资源是企业的第一资源 的管理理念, 摆脱人力资源管理是 “搞接待、做服务、 打考勤、算工资” 的劳资行政辅助部门的传统思维, 意识到人力资源管理是企业研发、栽培、加工、销售 等各项工作可持续发展的重要保证, 要提高人力资源 管理部门的管理层级, 明确人力资源部负责人为企业 的高管。再次, 对于处于高速发展的民营企业, 要注 意人力资源的管理水平要跟上企业发展的速度。具体 可以根据企业自身的发展战略确定人力资源管理的 定位, 构建出为满足企业战略的人力资源管理发展战 略目标和战略地图, 搭建人力资源管理的整体框架, 通过有效的人力资源管理来支撑公司的可持续发展 3。另外, 明确现代人力资源管理是企业经营活动中 关键的组成部分, 这就要求人力资源部门要主动参与 到企业经营中去, 确保人力资源部门成为企业各业务 部门的战略伙伴, 有效地实施人力资源战略, 为企业 提供人力资源方面对于企业战略制定的建议。最后, 民营企业要高度重视人力资源部的建设工作, 配置专 业化的人力资源管理人才, 选拨称职的人力资源经 理, 人力资源部门的职责就是为企业发展寻找人岗匹 配的专业化人才, 激发员工的热情和活力, 使员工安 心、舒心、放心地为企业服务。

\section{2 建立 “以人为本” 的人力资源管理制度}

首先, 民营企业离职率偏高, 而缺乏长远的人力 资源规划无疑是一个重要原因。企业应根据自身的条 件、目前的状况、未来的发展目标、员工的个性化需 求, 科学地预测人力资源需求, 在做好人力资源盘点 的基础上, 合理地规划企业短期、中期、长期所需要 的人才。短期通过招聘方式实现; 中期从基层选拔; 长期则需培养, 为实现企业的战略目标提供人才支 撑。其次, 在企业里营造出平等、开放、自由的工作 氛围，实现从“家族文化” 到 “民主文化”、从 “打 工文化” 到 “合作文化” 的转变, 使家族员工与外聘 员工之间形成互帮互助、合作共赢的团队精神, 增强 企业的凝聚力。再次, 第一、明确各个部门、每个岗 位的职责分工, 做到事事有人管、人人有职责, 构建 各司其职的工作机制。第二, 人是现代企业管理的关 键, 要努力建立起 “以人为本” 的企业管理制度, 让 员工感觉有奔头、有希望, 激发他们的工作热情, 调
动员工的创造性和积极性, 提高产品质量和服务水 平。最后, 在民营企业, 绝大多数员工离职的原因并 不是眼前的工资待遇, 而是个人职业发展的前景。因 此, 为员工规划好的职业生涯发展路径尤为必要, 不 仅可以帮助每位员工实现个人发展的愿望, 还可避免 企业发展与员工发展的偏差, 实现员工的自我价值与 企业发展的共赢。这就要求人力资源部门要找到人才 自我发展与企业目标的最佳契合点, 为每位员工都提 供广阔的上升通道, 使每一位员工都看到有个人发展 的希望, 为企业留才用才聚才。

\section{3 建立科学的招聘和员工培训制度}

第一、民营企业领导者应高度重视招聘工作，意 识到招聘这件日常琐碎工作的重要价值, 确保引进人 才的质量, 为企业高质量的发展提供有力支撑。这就 要求人力资源部门认真分析企业的岗位特点, 明确各 类岗位的岗位职责和任职要求 ${ }^{4}$, 综合运用人力资源 管理理论知识, 选取笔试、面试、背调等篎选方法和 测评工具, 根据业务部门的岗位需求, 制定相适宜的 招聘流程, 利用社招、高校和科研院所委培等多渠道、 科学合理地吸引、甄选、录用人才，提高招聘工作的 绩效, 降低人力资源的取得成本。第二、建立起科学 的招聘制度后, 还需要规范内部人员的晋升机制, 否 则只会造成优秀的人才留不住, 平庸的员工走不了, 长此以往, 企业就会变成一潭死水, 使前期的招聘工 作功亏一算。可采取管理职务和专业技术双通道、阶 梯晋升和破格提拔相结合、内部竞聘和举善荐贤等多 种晋升方式, 按照公平、公开、公正、透明的原则, 让每一位员工都有机会发挥自己的特长和潜能, 做到 人岗匹配、人尽其才、物尽其用。同时还要淘汰不合 格和落后的员工, 形成能上能下的竞争氛围, 使企业 永葆活力。第三、新产品的开发和技术的创新需要高 科技人才研发、设计; 生产的顺利进行和产品质量的 提高需要熟练的技术工人和普工操作、检验; 企业的 财务管理和市场营销需要高素质的管理人员组织、开 拓。因此, 民营企业的人力资源部门要科学合理地为 企业配置不同种类、不同层次的人才，并做到持证上 岗, 确保企业生产的安全运行和产品质量的优良。第 四、加强员工的继续教育与培训工作。民营企业要转 变投入资金为员工带薪培训获得技能, 是为 “他人做 嫁衣” 的思想局限, 对于新员工, 适应性和稳定性都 不足, 入职培训可使其了解企业的发展历程、岗位职 责、规章制度及行为准则, 帮助新员工尽快地度过适 应期, 融入团队。对于老员工, 为满足市场变化和技 术发展的要求, 结合企业的实际情况和员工能力素质 模型, 积极开展以提升组织绩效为目的相关培训, 学 习产品相关的新工艺、新技术，与员工约定服务期并 签订协议，促进工作效率的提升和组织目标的实现。

\section{4 建立多元化的立体激励机制和多层次的薪 酬体系}

员工激励是多元化和多角度的, 激励机制的优劣 
与民营企业的兴衰成败密不可分。首先, 要为不同层 级的员工制定不同层次的薪酬体系。对于企业高管采 取基础月薪和绩效年终工资的年薪制, 基础月薪以公 司员工近一年的平均工资为基数，绩效年终工资与企 业营业额、年度利润等指标挂钩; 对于专业技术人员 采用基本岗位工资+技术等级工资 +项目利润提成组 合而成的综合薪酬制; 对于普通员工实行以业绩目标 完成度的绩效工资制, 其薪酬构成为: 基本工资 + 绩 效工资。另外, 作为对薪酬的一项补充, 结合员工个 人不同的情况, 为员工们发放津贴、旅游、补助、礼 物等各种福利, 提高员工的 “获得感” 。其次, 给予 员工多元化的精神激励。第一、领导要主动地关心员 工、了解员工的想法和感受, 拉近与员工之间的距离, 使员工有苦有处说, 有难有地讲, 让员工感受到温暖, 增强对企业的归属感。第二、向全体员工开展企业文 化体系的培训, 将企业的核心价值观和企业精神牢牢 扎根于每位员工的心中, 使每个员工都衷心认同本企 业的价值取向和行为准则, 提高员工的整体素养 ${ }^{5}$ 。 第三、通过针对不同岗位设立诸如技术能手、优秀员 工、销售冠军、管理标兵等一系列的荣誉称号, 满足 员工自我实现的心理需求, 为员工提供展示自己的能 力和挑战自我的平台, 激发员工自我价值实现的自豪 感。再次, 对于初创型民营企业, 可运用股权激励的 方法, 通过设定工作年限或完成某个工作目标为附带 条件, 给对企业发展最有帮助的核心员工分配一些公 司股权, 将其吸纳为公司的股东, 从而使其能分享到 企业发展带来的经济效益与股东权利, 与企业结成长 期的利益共同体, 使核心员工为企业的长远发展勤勉 尽责地努力工作。

\section{4. 结论}

民营企业要充分认识到人力资源是第一资源的 重要性, 重视人力资源的开发和利用, 采取积极有效 的人力资源管理策略, 建立充满生机与活力的人力资 源管理机制, 开展科学的招聘和员工培训, 运用多元 化的立体激励机制和多层次的薪酬体系, 使民营企业 在激烈的市场竞争中立于不败之地。

\section{REFERENCES}

[1] Peng Ling. Discussions on the Current Status and Management Countermeasures of Internal Control of Private Enterprises, China Economic and Trade, 2020 (2) : 78-79.

[2] Problems and Improvement Countermeasures of Human Resource Management in the New Age, Journal of Jishou University (Social Science Edition), 2018, 39:82-84.

[3] Wang Xiaoyan, Gu Ying. Innovations of Human Resource Management in Small and Micro Enterprises, People's Forum, 2019 (9): 88-89.

[4] Zhou Guoliang.Exploration and Research on management standardization of Baihetan
Construction Bureau, Hunan Journal of water resources and hydropower, 2019 (6) :51-53.

[5] Cheng Long.Research on the core staff incentive of Qinhuangdao Ocean Shipping Agency Co., Ltd, Master Thesis of Yanshan University, 2018:18-20. 